\title{
Propagação de três genótipos de abieiro (Pouteria caimito) por estaquia de ramos herbáceos
}

\author{
Eduardo José de ALMEIDA ${ }^{1}$, Natanael de JESUS², Eliana Mayra Torrecillas SCALOPPI ${ }^{3}$, Antonio Baldo \\ Geraldo MARTINS ${ }^{4}$, Marcos Schwank ARAÚJO5 \\ RESUMO \\ Foram selecionadas três plantas de um pomar comercial, com características agronômicas desejáveis, proveniente de propagação \\ seminífera, que forneceram estacas herbáceas, contando com cerca de $15 \mathrm{~cm}$ de comprimento, um par de folhas no nó superior,

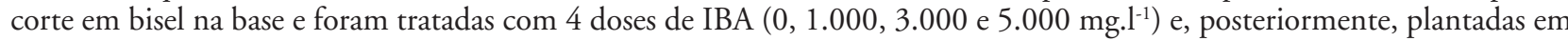 \\ caixas plásticas perfuradas contendo como substrato, vermiculita textura média. A condução do experimento foi em ambiente \\ de $50 \%$ de sombreamento, sob nebulização intermitente. A análise estatística foi em esquema fatorial 3X4, (genótipos X doses \\ de IBA), com 4 repetições de 10 estacas cada. Após 90 dias foram avaliados a percentagem de enraizamento e sobrevivência, \\ o comprimento e número médio de raízes por estaca. O IBA não influenciou as variáveis analisadas. O genótipo somente \\ induziu mais raízes na seleção 3 e maiores raízes nas seleções 1 e 3 .
}

PALAVRAS-CHAVE: Pouteria caimito, Propagação vegetativa, Estaquia, Regulador vegetal.

\section{Propagation of three abiu genotypes (Pouteria caimito) by cutting of herbaceous branches}

\begin{abstract}
Three plants from a commercial orchard Pouteria caimito were selected, with desirable agronomic characteristics, original of seed propagation, which provided the herbaceous branches. These ones were prepared with about $15 \mathrm{~cm}$ of length, a pair of leaves on the higher node and diagonal cut on the bottom, after that they were treated with four doses of indolbutiric acid (IBA) $\left(0,1,000,3,000\right.$ and 5,000 mg..$\left.^{-1}\right)$ and, then, planted on perforated plastic boxes, containing as substrate, medium texture vermiculite. The conduction of the trial was on a $50 \%$ shade doses), with 4 replicates of 10 branches each. After 90 days the percentage of rooting and survival, the length and average number of roots per branch were evaluated. The IBA has not influenced the analysed variables. The genotype has only induced a higher number of roots on the selection 3 and higher root length on the selections 1 and 3.
\end{abstract}

KEYWORDS: Native Fruits, Vegetative Propagation, Cutting, Vegetal Regulator

\footnotetext{
1 UNESP/FCAV, Depto. Produção Vegetal. Rod. Paulo Donato Castellane, s/n. CEP 14884-900, Jaboticabal-SP. Tel: (16)3209-2668. e-mail: eduardo.almeida@posgrad.fcav.unesp.br

2 UNESP/FCAV, Depto. Produção Vegetal Rod. Paulo Donato Castellane, s/n. CEP 14884-900, Jaboticabal-SP. Tel: (16)3209-2668. e-mail: natanael.jesus@fcav.unesp.br

${ }_{3}^{3}$ UNESP/FCAV, Depto. Produção Vegetal, Rod. Paulo Donato Castellane, s/n. CEP 14884-900, Jaboticabal-SP. Tel: (16)3209-2668. e-mail: emts@fcav.unesp.br

4 UNESP/FCAV, Depto. Produção Vegetal Rod. Paulo Donato Castellane, s/n. CEP: 14884-900, Jaboticabal-SP. Tel: (16)3209-2668. e-mail: baldo@fcav.unesp.br

${ }^{5}$ Eng. Agrônomo. Rua 16, 1144 - Centro, CEP 14780-050. Barretos-SP. e.mail: marcos.schwank@uol.com.br
} 


\section{INTRODUÇÃO}

Nas regiōes tropicais e subtropicais do mundo, existe grande número de espécie frutífera e dentre elas muitas têm atributos suficientes para serem aproveitadas comercialmente, pois produzem frutos e nozes de excelente qualidade para satisfazer os gostos mais exigentes. Hoje alguns países desenvolvidos, ávidos por frutas exóticas, importam estes produtos (Martel, 1992).

O abieiro (Pouteria caimito), espécie amazônica e pertencente à família das sapotáceas, é uma árvore de 5 a $6 \mathrm{~m}$ de altura, com folhas pecioladas, glabras e os frutos possuem forma ovóide ou esférica com casca amarela e lisa, às vezes amarela com estrias verdes, com massa entre 300 e $1.000 \mathrm{~g}$, polpa translúcida, branca ou amarela, mucilaginosa, doce ou insípida, contendo de 1 a 5 sementes grandes e lisas de cor preta e com grande aceitação popular, utilizado em sua maioria na forma in natura (Calzavara, 1970; Donadio, 1992).

Segundo Calzavara (1970), os tipos classificam-se quanto à forma do fruto quando maduro em redondo e comprido; quanto ao tamanho: grande, se superior a $600 \mathrm{~g}$; médio, se entre 300 e $600 \mathrm{~g}$; pequeno, se inferior a $300 \mathrm{~g}$. Este mesmo autor afirma, ainda, que o método de propagação mais utilizado é por sementes, mas podendo ser propagado vegetativamente pela enxertia com ótimos resultados, porém não menciona dados.

Segundo Martel (1992), apesar da importância destas espécies frutíferas nativas, pouco ou nada tem sido feito no sentido de torná-las competitiva através do melhoramento genético e do manejo agronômico. Almeida Neto (1988) citado por Sampaio (1992), obteve até $28 \%$ de enraizamento de estacas herbáceas provenientes de plantas adultas e $80 \%$ com estacas provenientes de planta juvenil ( 1 ano de idade). No entanto, apesar deste alto índice de enraizamento, as plantas manterão a juvenilidade fisiológica e, conforme ensina Hartman et al. (1997), a frutificação dessas árvores será mais demorada se comparada com plantas derivadas de estacas adultas.

Com objetivo de avaliar a capacidade de propagação vegetativa de abieiro pelo método de estaquia de ramos herbáceos, de 3 tipos selecionados, realizou-se o presente trabalho.

\section{MATERIAL E MÉTODOS}

O experimento foi realizado no Setor de Propagação de Frutíferas do Departamento de Produção Vegetal da UNESP/FCAV, Campus de Jaboticabal, na época do verão. O município de Jaboticabal localiza-se á latitude $21^{\circ} 15^{\prime} \mathrm{S}$ e longitude $48^{\circ} 18^{\prime} \mathrm{W}$, á altitude de cerca de $590 \mathrm{~m}$ acima do nível do mar. Com clima correspondente ao tipo Cwa na classificação de Köppen.
Três plantas de abieiro com boas características agronômicas foram selecionadas de um pomar localizado no município de Barretos, São Paulo, formado com mudas provenientes de sementes e que mostrava alta variabilidade genética. Nestas foram retiradas ramos enfolhados e em seguida levadas ao setor de propagação onde foram preparadas as estacas e plantadas no mesmo dia.

As estacas com consistência herbácea foram preparadas com cerca de $15 \mathrm{~cm}$ de comprimento, contando com 1 par de folhas inteiras no ápice e corte em bisel na base, com objetivo de aumentar a área de exposição ao regulador vegetal.

Os tratamentos consistiram em 3 genótipos (seleção 1, 2 e 3) e 4 doses do regulador vegetal ácido indolbutírico (0, $1.000,3.000$ e $\left.5.000 \mathrm{mg}^{-1} \mathrm{l}^{-1}\right)$. Após receberem os tratamentos as estacas foram plantadas em bandejas plásticas perfuradas de dimensão 30 X 20 X $14 \mathrm{~cm}$, contendo vermiculita textura média. As bandejas com as estacas devidamente plantadas foram acondicionadas e conduzidas em ambiente de ripado com $50 \%$ de luminosidade sob aspersão intermitente.

$\mathrm{O}$ experimento foi conduzido em delineamento inteiramente casualizado (DIC), com 4 repetições de 10 estacas cada, totalizando 480 estacas.

A avaliação foi realizada após 90 dias do estaqueamento, anotando as variáveis, número e comprimento médio de raízes por estaca (NR e CR, respectivamente) e percentagem de sobrevivência e enraizamento ( $\% \mathrm{~S}$ e $\% \mathrm{E}$, respectivamente). Os dados foram analisados em esquema fatorial $3 \mathrm{X} 4 \mathrm{e}$ as médias foram comparadas pelo teste de Tukey a $5 \%$ de probabilidade.

\section{RESULTADOS E DISCUSSÃO}

O IBA não influenciou estatisticamente a percentagem de enraizamento e sobrevivência (\%E e \%S, respectivamente). A tabela 1 apresenta os dados do enraizamento dos genótipos tratados pelas doses de IBA.

Estes resultados contrariam Almeida Neto (1988), citado por Sampaio (1992), em experimento com estacas enfolhadas de abieiro em ambiente de nebulização, que obteve com estacas de plantas provenientes de planta adulta, 14,36, 28 e $14 \%$ de enraizamento com as respectivas doses de IBA: 2.500, 5.000 e $10.000 \mathrm{mg} . \mathrm{l}^{-1}$, contudo esses resultados são inferiores aos encontrados neste experimento. Fachinello et al. (1995) afirmam que a potencialidade de uma estaca em formar raízes é variável com a espécie e cultivar, podendo ser feita uma classificação entre espécie ou cultivar em fácil, médio e difícil capacidade de enraizamento, ainda que a facilidade de enraizamento seja resultante da interação de diversos fatores e não apenas do potencial genético. Esta espécie em particular apresenta razoável facilidade de enraizamento, podendo credenciar os resultados conflitantes entre estas mesmas 
espécies à outros fatores como ambiente de cultivo. A literatura apresenta resultados semelhantes com outras espécies. Bastos et al. (2004) também não observaram efeito significativo de doses de IBA no $\% \mathrm{E}$ e $\% \mathrm{~S}$ de estacas de caramboleira.

Quanto ao número e comprimento de raízes (NR e CR, respectivamente), também, não foi observado efeito das doses do regulador vegetal. Estes resultados são contrários aos encontrados por Pereira et al. (1991) que observaram precocidade na iniciação radicular e maior número de raízes indicando efeito do regulador vegetal, em estacas herbáceas de goiabeira tratadas com IBA. 'Paluma' com $200 \mathrm{mg} . \mathrm{l}^{-1}$ obteve maior NR que com 100 e 400 mg. $\mathrm{l}^{-1}$. No entanto com a variedade Rica, observaram que a menor dose (100 mg. $\left.\mathrm{l}^{-1}\right)$ foi que proporcionou melhores resultados.

Não houve diferença significativa também para o genótipo de abieiro para as variáveis \%E e \%S. A constituição genética dos clones não resultaria em um potencial diferenciado de

Tabela 1 - Médias de percentagem de enraizamento e sobrevivência, número e comprimento médio de raízes de estacas herbáceas de abieiro (Pouteria caimito) em relação a doses de IBA (mg. I $\left.^{-1}\right)$. UNESP/FCAV, Jaboticabal - SP, 2005.

\begin{tabular}{|c|c|c|c|c|}
\hline $\begin{array}{l}\text { 으 } \\
\text { 브 }\end{array}$ & 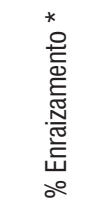 & 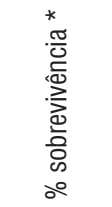 & 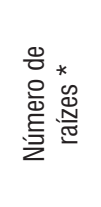 & 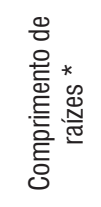 \\
\hline \multicolumn{5}{|c|}{ Seleção 1} \\
\hline 0 & $42,50 \mathrm{a}$ & $57,50 \mathrm{a}$ & $2,28 \mathrm{a}$ & $6,86 \mathrm{a}$ \\
\hline 1.000 & $45,00 \mathrm{a}$ & $66,67 \mathrm{a}$ & $1,99 a$ & $4,53 \mathrm{a}$ \\
\hline 3.000 & $65,00 \mathrm{a}$ & $70,00 \mathrm{a}$ & $2,38 \mathrm{a}$ & $10,04 \mathrm{a}$ \\
\hline 5.000 & $55,00 \mathrm{a}$ & $60,00 \mathrm{a}$ & $2,08 \mathrm{a}$ & $10,78 \mathrm{a}$ \\
\hline \multicolumn{5}{|c|}{ Seleção 2} \\
\hline 0 & $37,50 \mathrm{a}$ & $62,5 \mathrm{a}$ & $1,68 \mathrm{a}$ & $5,04 \mathrm{a}$ \\
\hline 1.000 & $47,50 \mathrm{a}$ & $82,5 \mathrm{a}$ & $2,48 \mathrm{a}$ & $6,52 \mathrm{a}$ \\
\hline 3.000 & $45,00 \mathrm{a}$ & $62,5 \mathrm{a}$ & $2,36 \mathrm{a}$ & $6,62 \mathrm{a}$ \\
\hline 5.000 & $50,00 \mathrm{a}$ & $62,5 \mathrm{a}$ & $2,38 \mathrm{a}$ & $5,86 \mathrm{a}$ \\
\hline \multicolumn{5}{|c|}{ Seleção 3} \\
\hline 0 & $57,50 \mathrm{a}$ & $59,44 \mathrm{a}$ & $2,54 \mathrm{a}$ & $10,02 \mathrm{a}$ \\
\hline 1.000 & $52,50 \mathrm{a}$ & $62,50 \mathrm{a}$ & $2,42 \mathrm{a}$ & $9,19 \mathrm{a}$ \\
\hline 3.000 & $62,50 \mathrm{a}$ & $70,00 \mathrm{a}$ & $3,05 \mathrm{a}$ & $10,65 a$ \\
\hline 5.000 & 66,67 a & $80,34 \mathrm{a}$ & $3,22 \mathrm{a}$ & $11,42 \mathrm{a}$ \\
\hline Cv (\%) & 27.1069 & 15.3710 & 9.4990 & 10.5987 \\
\hline
\end{tabular}

* Médias seguidas pela mesma letra, não diferem entre si pelo teste de Tukey $(\mathrm{P}<0,05)$. Dados originais. emissão de raízes. Já Tofanelli et al. (2003) encontraram diferenças significativas entre cultivares de pessegueiro tratadas em imersão rápida em doses de IBA, para \% $\mathrm{E}$ em que a cultivar Jóia 1 e Okinawa foram superior a 'Delicioso precoce'.

Porém a qualidade das raízes emitidas, na forma de comprimento e número médio de raízes ( $\mathrm{CR}$ e NR, respectivamente) foi influenciada pelo genótipo. A seleção 3 apresentou estatisticamente maior NR que as seleções 1 e 2 . As seleçôes 1 e 3 apresentaram maior CR que seleção 2 (Tabela 2). Estes resultados concordam com Tofanelli et al. (2003) que observaram para variável NR que a cv. Jóia 1 de pessegueiro superou 'Okinawa' que superou 'Delicioso Precoce'. O CR foi maior com cv. Jóia 1 e 'Okinawa' do que com 'Delicioso Precoce' e, também, são aos valores observados por Pio et al. (2004) que, em marmeleiro, obtiveram diferenças significativas entre cultivares na emissão de raízes adventícias em que a cultivar Portugal apresentou 12,12 raízes, distinguindo-se de 'Radiolo' e 'Pineaple' (9,15 e 7,00, respectivamente). O comprimento de raízes também apresentou distinção entre cultivares, mostrando, como neste trabalho, a capacidade diferencial de formação de raízes inerentes aos diferentes tipos ou variedades de fruteiras.

Tabela 2 - Médias de percentagem de enraizamento e sobrevivência, número e comprimento de raízes de estacas herbáceas de abieiro (Pouteria caimito) em relação á genótipos (mg.|-1). UNESP/FCAV, Jaboticabal - SP, 2005.

\begin{tabular}{|c|c|c|c|c|}
\hline $\begin{array}{l}\text { 으 } \\
\text { 므 }\end{array}$ & 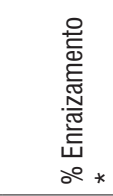 & 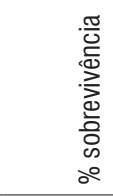 & 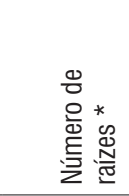 & 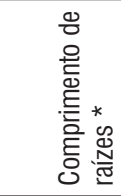 \\
\hline 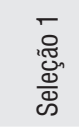 & $51,88 \mathrm{a}$ & $63,54 \mathrm{a}$ & $2,18 \quad b$ & $8,05 \mathrm{a}$ \\
\hline 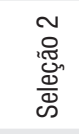 & $45,00 \mathrm{a}$ & $67,5 \mathrm{a}$ & $2,22 \mathrm{~b}$ & $6,01 \quad b$ \\
\hline 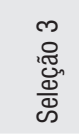 & $59,79 a$ & $68,07 \mathrm{a}$ & $2,81 \mathrm{a}$ & $10,32 \mathrm{a}$ \\
\hline Cv (\%) & 27.1069 & 15.3710 & 9.4990 & 10.5987 \\
\hline
\end{tabular}

* Médias seguidas pela mesma letra, não diferem entre si pelo teste de Tukey $(\mathrm{P}<0,05)$. Dados originais. 


\section{CONCLUSÕES}

A propagação vegetativa por estaquia é perfeitamente recomendável para as seleçôes avaliadas sem o uso de regulador vegetal (IBA);

A seleção 3 apresenta maior número de raízes e as seleções 3 e 1 apresentam maior comprimento de raízes.

\section{LITERATURA CITADA}

Bastos, D.C. 2004. Efeito da época de coleta, estádio do ramo e do tratamento com IBA no enraizamento de estacas de caramboleira (Averrhoa carambola L.). Revista Brasileira de Fruticultura, 26 (2): 212-216.

Calzavara, B.B.G. 1970. Fruteiras: Abieiro, Abricozeiro, Bacurizeiro, Biribazeiro, Cupuaçuzeiro. Instituto de Pesquisa e Experimentação Agropecuária do Norte. Série culturas da Amazônia, 1(2): 84.

Donadio, L.C.; Martins, A.B.G.; Valente, J.P. 1992. Fruticultura Tropical. Jaboticabal: Funep. 268pp.

Fachinello, J.C.; Hoffmann, A.; Nachtigal, J.C.; Kersten, E.; Fortes, G.R.L. 1995. Propagação de plantas frutíferas de clima temperado. 2. ed. Pelotas: UFPel. 178pp.

Martel, J.H.I. 1992. Frutíferas da Amazônia. In: Donadio, L.C.; Martins, A.B.G.; Valente, J.P (Eds). Fruticultura Tropical. Jaboticabal: Funep. 268pp.
Pereira, F.M.; Petrechen, E.H.; Benincasa, M.M.P.; Banzatto, D.A. 1991. Influência do ácido indol butírico no enraizamento e estacas herbáceas de goiabeira (Psidium guajava L.) das cultivares Rica e Paluma, em câmara de nebulização. Científica, 19(2): 199-206.

Pereira, F.M.; Martinez Jr., M. 1986. Goiabas para industrialização. Jaboticabal: Legis Summa, 137pp.

Pio, R.; Araújo, J.P.C.; Scarpare Filho, J.A.; Mourão Filho, F.A.A.; Alvarenga, A.A.; Abrahão, E. 2004. Potencial de propagação de cultivares de marmeleiro por estaquia. Revista Brasileira de Fruticultura, 26(2): 287-289.

Sampaio, V.R. 1992. Propagação das frutíferas tropicais. In: Donadio, L.C.; Martins, A.B.G.; Valente, J.P. (Eds.). Fruticultura Tropical. Jaboticabal: Funep. 268pp.

Tofanelli, M.B.D.; Ono, E.O.; Rodrigues, J.D. 2003. Método de aplicação de ácido indolbutírico no enraizamento de estacas herbáceas de pessegueiro. Revista Brasileira de Fruticultura, 25 (2): 363-364.

Recebido em 17/05/2006

Aceito em 16/05/2007 